\title{
Reduction cost and energy consumption for led smart lighting street technology in Iraq
}

\author{
Jabbar K. Mohammed \\ Communication Engineering Department, University of Technology-Iraq, Iraq
}

\begin{tabular}{l}
\hline \hline Article Info \\
\hline Article history: \\
Received Feb 13, 2020 \\
Revised Apr 9, 2020 \\
Accepted Apr 23, 2020
\end{tabular}

\section{Keywords:}

Energy efficiency

LED lamps

Renewable energy

Smart lighting

Total ownership cost (TOC)

\begin{abstract}
The idea of replacing the old lighting system with energy-efficient ones has been given excessive attention, particularly in the territorial and Arabic world. This move is significant for its helpful effects on both the economy and the environment, especially in Iraq which smarts from light-related problems. It correspondingly aids the light distribution offices as it will save them from several light generation troubles and their effects on the hours of electrical power supply. The light consumers will also benefit from reduced bills due to approximately $50 \%$ reduction in power consumption by the energyefficient system. The energy-efficient lighting system has replaced the traditional technical lighting owing to its energy saving capability and environmental friendliness. These problems would enhance the use of efficient energy programmer to reduce energy consumption as the world switches to the use of renewable energy. This study presents the use of modernized lighting system with an emphasis on its economic and environmental benefits. The results are applied by MATLAB version17b prototypical is built to evaluate the behavior of smart lighting street technology and renewable energy to reduce cost and energy consumption. During the study, 100 modernized LED electric lamps of $150 \mathrm{~W}$ capacity were used to replace 100 high pressure sodium (HPS) lamps of 400W. The economic cost of the replacement was calculated based on the price of the LED lamps compared to those of the HPS lamps. The environmental impact was determined by calculating the global cost of the electrical energy consumed by the LED lamps compared to those consumed by the HPS lamps in Iraq.
\end{abstract}

Copyright $(0) 2020$ Institute of Advanced Engineering and Science. All rights reserved.

\section{Corresponding Author:}

Jabbar K. Mohammed,

Communication Engineering Department,

University of Technology-Iraq, Baghdad, Iraq.

Email: 11021@uotechnology.edu.iq

\section{INTRODUCTION}

The quality of life in a city can be improved by embracing advanced street lighting techniques which guarantees low emissions and radiations. It also provides a sense of safety, reduces crime, and encourages a longer use of public grounds for several activities. It is the responsibility of the local government to provide or influence the provision of street and public lighting [1]. Public lighting contributes significantly to the energy consumption of a city; however, energy consumption within a city can be reduced by using renewable energy and energy-efficient techniques in street lighting.

These techniques can also save cost and minimize the emission of harmful gases to the environment. Areas that have no electricity infrastructure can rely on renewable energy solutions can as an easy lighting option, especially in the rapidly developing areas or the under-developed city areas. Various actions can be implemented by the local government to enhance public lighting across a city. Some of these applications can be used independently while others may need to be used within an integrated programmed, such as stand-alone against grid-integrated photovoltaic (PV). Some of the available options to the local government are as follows [2]: 
a) Stand-alone PV powered lighting: They do not utilize energy from an electricity grid, hence, they are self-contained systems with the advantage of being easy to install. Compared to the grid-interactive street lights, this system can reduce the running and maintenance costs. Solar lights operate at low voltages; hence, they are reliable and a safe option for workers.

b) Grid-interactive PV powered lighting: This system adds to the electricity grid during the day and derives from it during the night. Lighting can be considered as a smart grid that deploys information and communication technology to collect performance information (e.g. the light switching on only when the intensity of the natural daylight is below a given threshold). This system may not be ideal in many applications such as wind farm and solar power plant.

c) Renewable energy (RE) procurement: The amount of electricity required to light the street can be procured and fed to the general electricity grid from a remote RE source. This could further support the production of RE within the region and be a part of the effort towards shifting local government operations to RE.

d) Promote energy conservation and efficiency: The consumption of energy can be minimized by amending the operation hours, the power, and the number of street lights. This process involves no additional cost. Furthermore, the existing lighting can be replaced with more energy-aware lighting systems, such as LED lamps [3].

The use of LEDs started in the 1990s when incandescent-based traffic lights along the cities in the U.S.A and Europe were replaced with highly energy-efficient lamps. Today, LEDs are presenting as the alternative towards tackling street lighting challenges. LED street lights are being installed and tested around the world, especially in China, Europe, and North America where efforts are made to replicate the advantages of LED traffic lights (cost and energy saving) achieved elsewhere [4]. More than one of these options can be adopted by the local governments based on their local circumstances and priorities but the major differences lie on the current regulatory outline, initial installation costs, infrastructure, and the available investment. The actions of the local government can also be limited, especially when it is the responsibility of the state or national government to provide street lights [2].

In doped material, the presence of an extra atom alters the electron equilibrium by either adding free electrons or generating electron holes to trap electrons. Both conditions improve the conductivity of the material. $\mathrm{N}$-type materials are semiconductors with extra electrons. They are called N-type because of the presence of extra negatively-charged particles. In this arrangement, electricity is conducted only in one direction. In situations where no voltage is supplied to the diode, the holes on the P-type material will be filled by electrons from the N-type material to form a depletion zone along the junction between the layers. The semiconductor material in the depletion zone is reverted to its preliminary insulation condition as whole the electron bores will be filled which means no empty spaces exist for free electrons and as such, resisting charge flow [5].

The connection of the P-type side to the circuits' negative station and the N-type side to the positive station resists current flow as shown in Figure 1. The positive electrode attracts the negative electrons in the $\mathrm{N}$-type material while the negative electrodes attract the positive holes in the P-type material. Hence, there will be no current flow across the junction since electrons from both ends are moving in the incorrect way, thereby increasing the depletion zone Figure 2.

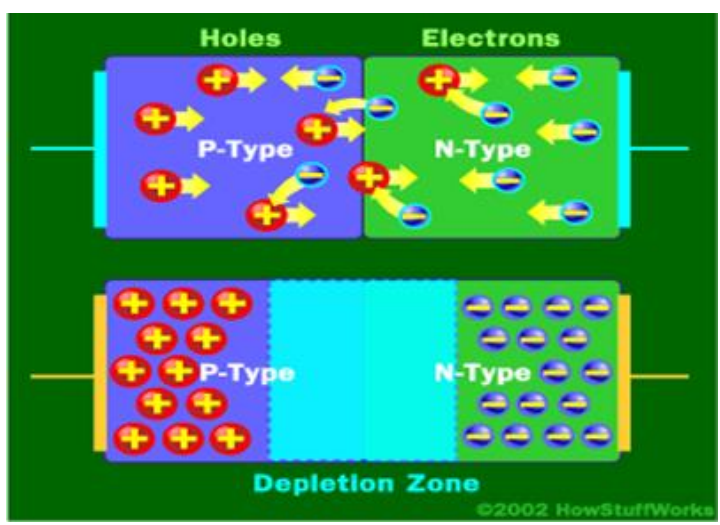

Figure 1. The fill holes by the P-type material (depletion zone) and at the junction, free electrons from the N-type material [5]

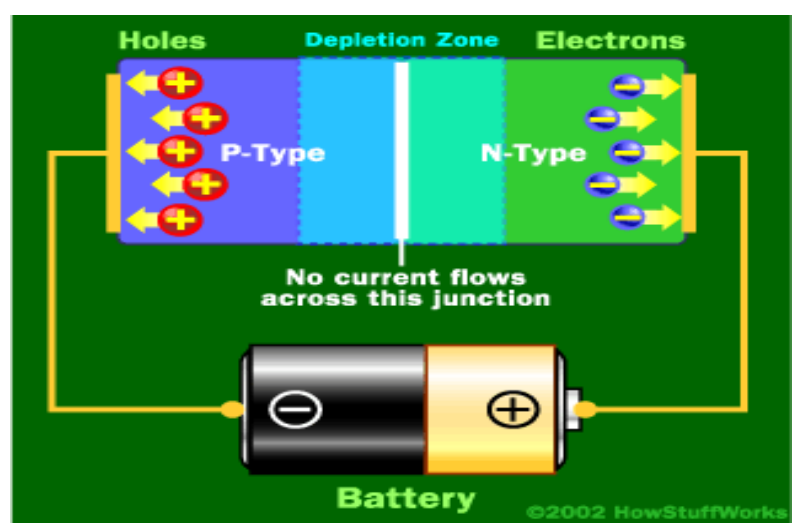

Figure 2. The positive electrode attracts the negative electrons in the N-type material while the negative electrodes attract the positive holes in the P-type material [5] 
Light as an energy form cannot be restricted via the atom since it is composed of numerous tiny element such as packages that have no mass but with energy and momentum [5]. Because of the orbital decline from the transmission band to reducing orbit, energy is released by the electrons as photons. This is obtainable in any diode, but the photons can be achieved when the diode was made up of assured materials. For instance, in the typical silicon diode, the atoms have been organized in a manner that the electron can only drop a reasonably short distance. This is not really a wicked object since infrared LEDs are mainly suitable for isolated controls, surrounded by further effects. A segment that marks the coexistence between luminaires and trees is contained in the methodological regulation of lighting and street lighting (RETILAP) [6] from Colombia. Hong Kong's Public Lighting Design Manual [7] presents the technique for arranging the mounting height of luminaire. This manual also expressed the distance between fire hydrants and luminaires to ensure no blockage in the process.

\section{MATERIALS AND METHODS}

Several inorganic semiconductors are used to develop traditional LEDs. Table 1 presents the available colors, their range of wavelength, the voltage drops, and the semiconductor material [8].

Table 1. Colors and materials with different wavelengths and voltage drops

\begin{tabular}{|c|c|c|c|}
\hline Color & Wavelength [nm] & Voltage drop $[\Delta \mathrm{V}]$ & Semiconductor material \\
\hline Infrared & $\lambda>760.0$ & $\Delta \mathrm{V}<1.630$ & Gallium arsenide (GaAs) Aluminum gallium arsenide (AlGaAs) \\
\hline Red & $610.0<\lambda<760.0$ & $1.630<\Delta \mathrm{V}<2.030$ & $\begin{array}{l}\text { AlGaAs, Gallium arsenide phosphate (GaAsP), Aluminum gallium } \\
\text { indium phosphate (AlGaInP), Gallium (III) phosphate }(\mathrm{GaP})\end{array}$ \\
\hline Orange & $590.0<\lambda<610.0$ & $2.030<\Delta \mathrm{V}<2.100$ & GaAsP, AlGaInP, GaP \\
\hline Yellow & $570.0<\lambda<590.0$ & $2.100<\Delta \mathrm{V}<2.180$ & $\mathrm{GaAsP}, \mathrm{AlGaInP}, \mathrm{GaP}$ \\
\hline Green & $500.0<\lambda<570.0$ & $1.90<\Delta \mathrm{V}<4.00$ & $\begin{array}{l}\text { Traditional green: GaP, AlGaInP, Aluminum gallium phosphate } \\
\text { (AlGaP) Pure green: Indium gallium nitride }(\mathrm{InGaN}) / \mathrm{Gallium} \text { (III) } \\
\text { nitride }(\mathrm{GaN})\end{array}$ \\
\hline Blue & $450.0<\lambda<500.0$ & $2.480<\Delta \mathrm{V}<3.70$ & $\begin{array}{l}\text { Zinc serenade ( } \mathrm{ZnSe}) \text {, InGaN, Silicon carbide ( } \mathrm{SiC}) \text { as substrate, } \\
\text { Silicon }(\mathrm{Si}) \text { as substrate (upcoming) }\end{array}$ \\
\hline Violet & $400.0<\lambda<450.0$ & $2.760<\Delta \mathrm{V}<4.00$ & $\mathrm{InGaN}$ \\
\hline Purple & multiple types & $2.480<\Delta \mathrm{V}<3.70$ & $\begin{array}{l}\text { Dual blue/red LEDs, blue with red phosphor, or white with purple } \\
\text { plastic }\end{array}$ \\
\hline Ultraviolet & $\lambda<400.0$ & $3.10<\Delta \mathrm{V}<4.40$ & $\begin{array}{l}\text { Diamond (235nm), Boron nitride }(215 \mathrm{~nm}) \text {, Aluminum nitride } \\
(210 \mathrm{~nm}), \mathrm{AlGaN}, \mathrm{AlGaInN} \text { (down to } 210 \mathrm{~nm})\end{array}$ \\
\hline Pink & multiple types & $\Delta \mathrm{V} \sim 3.30$ & Blue with 1 or 2 phosphor layers: yellow with red \\
\hline White & Broad spectrum & $\Delta V=3.50$ & Blue/UV diode with a yellow phosphor \\
\hline
\end{tabular}

The energy efficiency of two solutions was evaluated and compared based on the combine and exact method. The evaluation was done by computing the total power consumption $P_{t o t}$, and assuming the linear dependency of the total luminous flux of LED fixture on the provided power [9]:

$$
\frac{P i}{P \text { norm }, i}=\frac{\emptyset i}{\emptyset \max , i} \equiv L F R i
$$

where $P$ nom $i=$ nominal power of the $i$-th fixture, $\Phi \max$, $i=$ total luminous flux touched for $P$ nom, $i$ provided, $\Phi i=$ total luminous flux for $P i$ and $L F R i=$ the corresponding dimming constant such that $L F R \quad i=0$ and $L F R i=1$ characterize fully dimmed and non-dimmed states. Constructing such an assumption will give:

$$
\text { Psav }=\sum_{i=0}^{N} p i=\sum_{i}^{N} L F R \text { i Pnorn }, i .
$$

The relative power reduction, which is the measurable amount of the value of the solution is designed as:

$$
P \operatorname{sav}=\frac{\text { Pnorm }- \text { P Tot }}{P \text { norm }}=\frac{\sum_{i=1}^{N}(1-\text { LFR } i) \text { Pnorn }, i}{\sum_{i=1}^{N} \text { Pnorn }, i}
$$

Note that $P s a v \in[0,1]$. For two solutions, the solution with a higher $P$ sav is the better one. The key benefit of stabilizer lighting classifications is that they can evade overvoltage situations. The study carried out by [7] presented how the nominal voltage value was stretched to as high as $246 \mathrm{~V}$ despite that this value is recognized at $230 \mathrm{~V}$ in Spain. This overvoltage is the major cause of shortened lamps lifetime. Regulator and stabilizer devices as shown in Figure 3. 


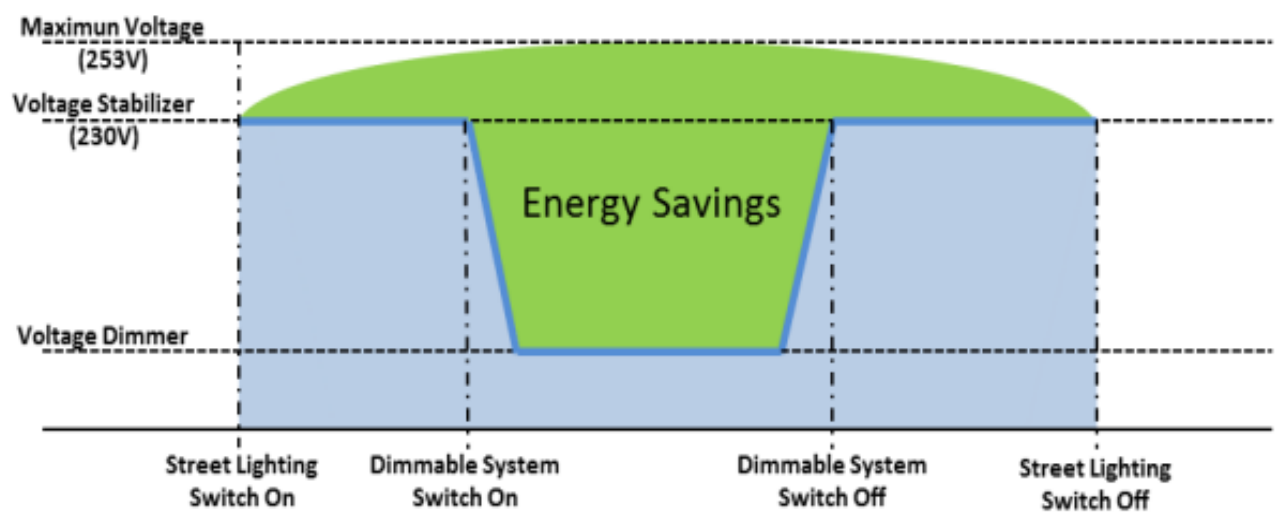

Figure 3. Regulator and stabilizer devices [9]

\subsection{Street lighting technology comparison}

High-intensity discharge lamps (such as HPS lamps) are commonly used in street lighting these days. These lamps provide high photonic illumination at the least electricity consumption. However, the nonsuitability of HPS lamps is usually evidenced once photonic/scotopic light evaluations are utilized for night lighting. Being that the light sources doubles the peripheral vision of road users and increase their brake reaction time by a minimum of $25 \%$, it becomes necessary that when using S/P light designs, the performance of HPS lamps must be concentrated by at least $75 \%$ [10].

A study has reported that a street lighted by lighting system made of metal halide was reliably brighter and safer at night compared to the same scene under HPS illumination. The new street lighting technologies like LEDs emit white light with high scotopic lumens levels which facilitates street lights with lower power wattages; they also emit lower photonic lumens as alternatives to the existing street lights. Figure 4 presents LED vs HID life and lumen maintenance with years while Figure 5 shows the results and simulation of those calculations [11].

About $90 \%$ of the utilized energy by an incandescent lamp is lost as heat while $<10 \%$ is involved in light production. They are mainly used in areas that are prone to frequent vandalism or theft as they can be easily replaced if damaged or stolen; elsewhere, they are wasteful since LED systems that use 7 times less energy can provide 5\% energy efficiency and a few hundred hours' lifespans. Furthermore, a re-strike time of about 5-10minutes is needed every time the light is switched on before it can be switched off. Hence, they are not suitable for environments that deploy intelligent light control systems [13]. The average service life of MH lamps is about 10,000-12,000h. Another problem is that these lamps contain mercury and lead. A 1500 watts $\mathrm{MH}$ lamp contains about $1 \mathrm{~g}$ of mercury. Their low life hours and high cost have restricted their usage in municipal lighting despite their much-improved CRI of about 85 [14].

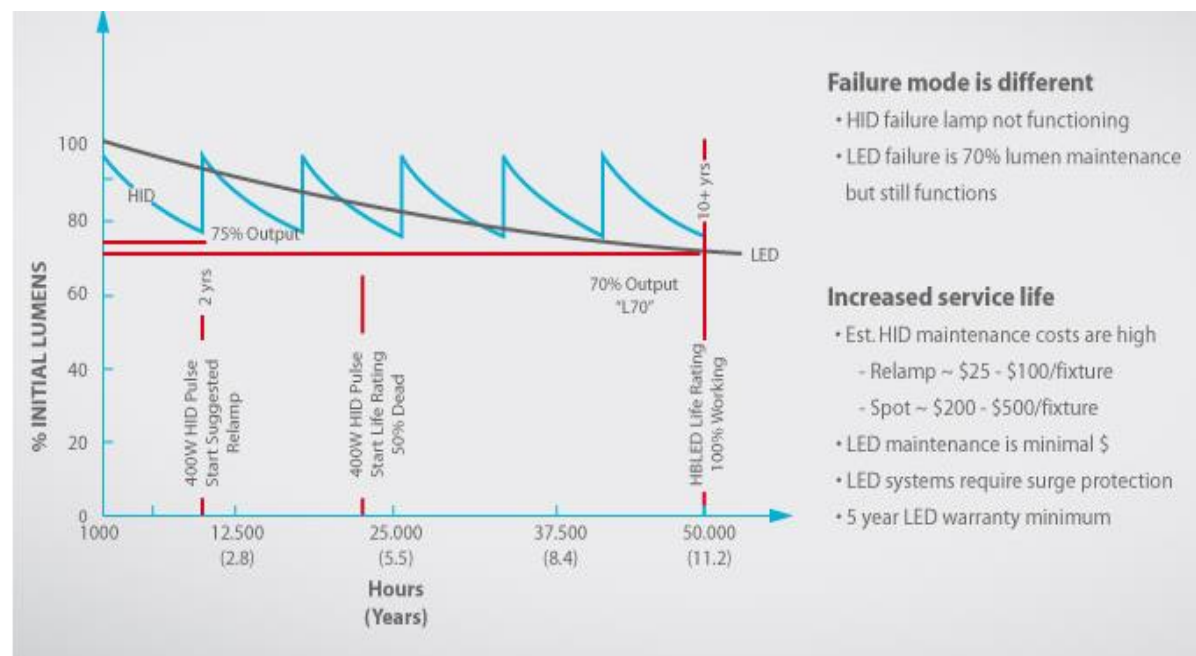

Figure 4. LED vs HID life and lumen repairs with years [11] 


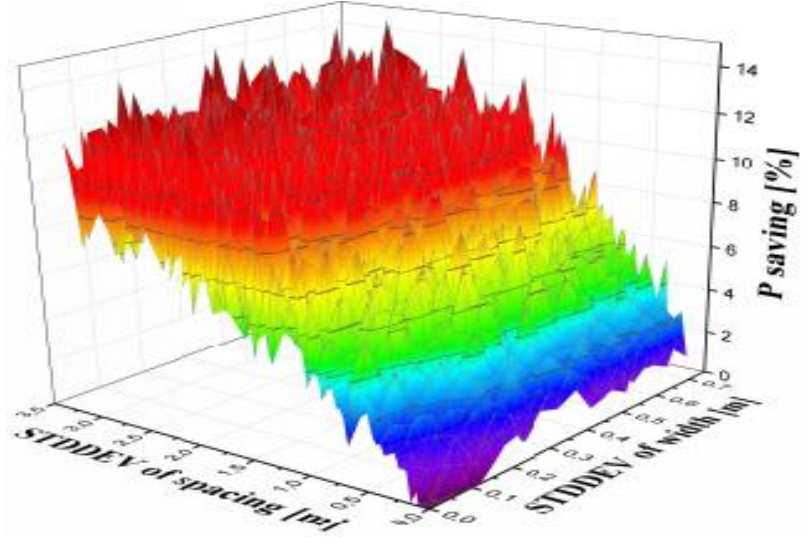

Figure 5. 3D plot of power savings as a function of the average deviations of spacing and standard of width [12]

With the improvement in the quality of compact fluorescent lamps (CFL), they have been commonly used in recent times; however, there is still a need to improve on their reliability. Some of the problems of CFL are high heat buildup in the self-contained ballast, limited lumen output, low life/burnout due to frequent lamp (on/off) cycling, and sources becoming dimmer in cold conditions. They are also mercurycontaining but with excellent CRI of around 85 and a very high CFL efficiency. They produce white soft light at a color temperature of around $3000 \mathrm{~K}$. They can also produce higher color temperatures [15]. Different lighting technologies and their lifetime as shown in Table 2.

Table 2. Different lighting technologies and their lifetime

\begin{tabular}{|c|c|c|c|c|c|c|}
\hline $\begin{array}{l}\text { Lighting } \\
\text { technology }\end{array}$ & Lifetime & $\mathrm{Ls} / \mathrm{w}$ & $\mathrm{CT}$ & CRI & IT & Considerations \\
\hline $\begin{array}{l}\text { Incandescent } \\
\text { light }\end{array}$ & $1.00-5.00$ & $11.0-15.0$ & $2.80 \mathrm{~K}$ & 40.0 & Instant & Highly inefficient, limited life time \\
\hline $\begin{array}{l}\text { Mercury vapor } \\
\text { light }\end{array}$ & $12.00-24.00$ & $13.0-48.0$ & $4.00 \mathrm{~K}$ & $\begin{array}{l}15.0- \\
55.0\end{array}$ & $\begin{array}{l}\text { About } 15 \\
\text { min }\end{array}$ & $\begin{array}{l}\text { Highly inefficient, emits mercury- } \\
\text { containing ultraviolet radiation }\end{array}$ \\
\hline $\begin{array}{l}\text { Metal halide } \\
\text { light }\end{array}$ & $10.00-15.00$ & $60.0-100.0$ & $3.00-4.30 \mathrm{~K}$ & 80.0 & $\begin{array}{l}\text { About } 15 \\
\min \end{array}$ & $\begin{array}{l}\text { Requires high maintenance, emits } \\
\text { mercury-and lead containing UV radiation, } \\
\text { can burst at expiration }\end{array}$ \\
\hline HPS light & $12.00-24.00$ & $45.0-130.0$ & $2.00 \mathrm{~K}$ & 25.0 & $\begin{array}{l}\text { About } 15 \\
\min \end{array}$ & $\begin{array}{l}\text { Has a low CRI, emits mercury and lead- } \\
\text { containing yellow light }\end{array}$ \\
\hline $\begin{array}{l}\text { Low pressure } \\
\text { sodium light }\end{array}$ & $10.00-18.00$ & $80.0-180.0$ & $1.80 \mathrm{~K}$ & 0.0 & $\begin{array}{l}\text { About } 15 \\
\min \end{array}$ & $\begin{array}{l}\text { Has a low CRI, emits mercury and lead- } \\
\text { containing yellow light }\end{array}$ \\
\hline $\begin{array}{l}\text { Fluorescent } \\
\text { light }\end{array}$ & $10.00-20.00$ & $60.0-100.0$ & $2.70-6.20 \mathrm{~K}$ & $\begin{array}{l}70.0- \\
90.0\end{array}$ & $\begin{array}{l}\text { About } 15 \\
\min \end{array}$ & $\begin{array}{l}\text { Prone to glass breaking, emits mercury- } \\
\text { containing UV radiation. }\end{array}$ \\
\hline $\begin{array}{l}\text { Solid } \\
\text { fluorescent } \\
\text { light }\end{array}$ & $12.00-20.00$ & $50.0-72.0$ & $2.70-6.20 \mathrm{~K}$ & 85.0 & $\begin{array}{l}\text { About } 15 \\
\min \end{array}$ & $\begin{array}{l}\text { Easily burnout due to low life, dimmer in } \\
\text { cold conditions }\end{array}$ \\
\hline Induction light & $60.00-100.00$ & $70.0-90.0$ & $2.70-6.50 \mathrm{~K}$ & 80.0 & Instant & $\begin{array}{l}\text { The initial cost is high, limited } \\
\text { directionality, lead-containing, affected } \\
\text { negatively by heat. }\end{array}$ \\
\hline LED light & $50.00-100.00$ & $70.0-150.0$ & $3.20-6.40 \mathrm{~K}$ & $\begin{array}{l}85.0- \\
90.0\end{array}$ & Instant & The initial cost is relatively higher \\
\hline
\end{tabular}

Note: $\mathrm{CRI}=$ color rendering index, $\mathrm{CT}=$ color temperature, $\mathrm{IT}=$ ignition time, Ls/w=lumens/watt

\subsection{Differences between low and high-quality LED streetlights}

Many developments have been experienced in LED technology over the last few years. LED lighting luminary production is a difficult task that requires the services of several advanced production lines and demands the use of top quality materials and a highly precise made-up procedure. There are only a few factories in the world which have met the required qualitative standards for LED lamps production. With the advancements in LED technology, several inexperienced LED street light producers have flooded the market. A poorly manufactured LED street light is not as good as than any further type of obtainable energy-saving lamps currently available, while a high-quality LED is better than any of the existing lamps in all the methodological constraints. Currently, 
there are less than 100 qualified LED street lights manufacturers globally and less than 10 of these manufacturers can produce high-quality LED street lamp, thereby optimally exploiting the complete benefits of LED technology [16]. Financing selections for effective street lighting as shown in Table 3.

Table 3. Financing selections for effective street lighting

\begin{tabular}{|c|c|c|c|c|c|}
\hline \multirow[t]{2}{*}{ Factors } & \multicolumn{2}{|c|}{ Self-financing } & \multicolumn{3}{|c|}{$\begin{array}{l}\text { ESCO Samples } \\
\end{array}$} \\
\hline & Debt financing & Equity financing & Shared savings & $\begin{array}{l}\text { Guaranteed } \\
\text { savings }\end{array}$ & $\begin{array}{c}\text { Annuity } \\
\text { payments }\end{array}$ \\
\hline Danger on investment to the host & $\mathrm{H}$ & $\mathrm{M}$ & $\mathrm{L}$ & $\mathrm{L}$ & $\mathrm{L}$ \\
\hline Use of best available technology & $\mathrm{L}$ & $\mathrm{L}$ & $\mathrm{H}$ & $\mathrm{H}$ & $\mathrm{H}$ \\
\hline $\begin{array}{l}\text { Operating \& performance risks to } \\
\text { the host }\end{array}$ & $\mathrm{H}$ & $\mathrm{H}$ & $\mathrm{L}$ & $\mathrm{L}$ & $\mathrm{MH}$ \\
\hline Monetary savings to the host & $\mathrm{H}$ & M & M & M & $\mathrm{L}$ (fixed) \\
\hline $\begin{array}{l}\text { Required investment by the host } \\
\text { customer }\end{array}$ & $\mathrm{H}$ & M & ---- & $\begin{array}{l}\text { Guaranteed } \\
\text { high yields }\end{array}$ & ---- \\
\hline
\end{tabular}

Note: $\mathrm{H}=$ high, $\mathrm{M}=$ moderate, $\mathrm{L}=$ low, $\mathrm{MH}=$ moderately high

\subsection{Overall advantages of high-grade LED streetlights}

Some of the paybacks of high-quality LED street lighting are as surveys:

a) Less energy consumption

LED have at least 5 times higher lifetime than HPS fixtures; they use 40-80\% less electricity compared to the HPS lamps. Compared to incandescent lamps, LED lamps are about 7 times more energy efficient and twice more than fluorescent lamps [17].

b) Higher efficiency

Lower lumen output LED street lights can replace the higher output conventional lamps. For instance, an 80W HPS lamp can be replaced with a 30W LED street light because of the directionality offered by LED lamps and their light output is higher, LED lamps have little or no hot spot and their light is directed downwards and spread over the covered area. This implies that LED lamps require a lower quantity of light to brighten an area properly, thereby reducing light pollution which can affect human modes, birds' navigation, animals' mating behavior, and flowering as well.

c) Long life of up to 100000 hours

LED street lights have a longer service life (3 to 8 times longer) than conventional lamps; hence, they reduce the cost and required labor for lamps replacement. The long-life span of LED lamps reduces the maintenance cost, thereby making them suitable for use in difficult locations and for streetlights when maintenance costs are considered [18].

e) Great operating characteristics

LED lamps can function at lower weather conditions (low temperatures) because they are insensitive to low temperature; they are also unaffected by the lamp on/off cycling, making them safer and more suitable in cold conditions applications that require frequent switching cycling. They are resistant to shocks, making them suitable for areas prone to vibration, like bridges.

f) Decreasing carbon footmark

LED street lights have a smaller carbon footprint compared to other lights because of its minimum energy usage. Furthermore, it lasts longer (4 to 10 times longer) than the other lamps, thereby decreasing the factories carbon footprint over the lifetime.

g) Dark sky friendly and Easily controllable

The directionality of LED lamps ensures that its light is carefully channeled to wherever it is destined to go. Hence, there is little or no light wastage to night sky illumination. This is important in environments where a dark sky inventiveness is considered [19].

h) Natural light shadow-Colour Adaptation Index

The LED lamps temp. (3.500-4.200K) produces more natural light compared to the HPS lamps which produce yellow light or the fluorescent streetlights that produce green light. LED lamps do not emit UV or IR radiation; they have a high color rendering index of 80-90 [19-21].

\section{RESULTS AND DISCUSSION}

\subsection{Financial feasibility study for using LED street lighting}

The feasibility study was based on the replacement of traditional 400 W HPS lamp bulbs with 100 LED lamp of $150 \mathrm{~W}$. Note that the prices and cost of replacement lamps have been adopted in accordance with international prices while and the cost of electricity consumed was as approved by the Ministry of Electricity [22-25]. In the case of LED-150W, the SMPS replacement period is 4 years and not the maintenance cost for 20 years. 
Table 4. Comparison of the cost of electricity based on the type of lamps

\begin{tabular}{lccc}
\hline \multirow{2}{*}{ Factors } & \multicolumn{2}{c}{ Based on 100 pcs quantity } & \multirow{2}{*}{ Remarks } \\
\hline Annual electricity cost & HPS light $(400 \mathrm{~W})$ & LED light $(150 \mathrm{~W})$ & \\
Electricity cost for 10 years & $21.000 \$$ & $7.880 \$$ & $13.120 \$$ \\
\hline
\end{tabular}

Table 5. Initial investment and total cost

\begin{tabular}{|c|c|c|c|}
\hline \multirow{2}{*}{ Factors } & \multicolumn{2}{|c|}{ Based on 100 pcs quantity } & \multirow{2}{*}{ Remarks } \\
\hline & HPS light (400W) & LED light $(150 \mathrm{~W})$ & \\
\hline Unit price & $200 \$$ & $700 \$$ & \\
\hline Total cost & $20.000 \$$ & $70.000 \$$ & \\
\hline \multicolumn{4}{|c|}{ Comparison of energy consumption } \\
\hline Daily electricity consumption & $57.53 \$$ & $21.58 \$$ & \\
\hline Annual electricity consumption & $21.000 \$$ & $7.880 \$$ & \\
\hline \multicolumn{4}{|c|}{ Operation extra spending (10 years) } \\
\hline Energy consumption cost & $210.000 \$$ & $78.800 \$$ & $131.200 \$$ \\
\hline Lam replacement cost & $25.000 \$$ & $16.000 \$$ & LED lamps need no replacement within 10 years \\
\hline Maintenance cost for 10 years & $75.000 \$$ & $16.000 \$$ & $59.000 \$$ \\
\hline Total & $330.000 \$$ & $164.800 \$$ & $165.200 \$$ \\
\hline
\end{tabular}

Table 6. Maintenance cost

\begin{tabular}{lccc}
\hline \multirow{2}{*}{ Factors } & \multicolumn{2}{c}{ Based on 100 pcs quantity } & \multirow{2}{*}{ Remarks } \\
\hline Annual maintenance cost & $7.000 \$$ & $1.600 \$$ & $1.600 \$$ \\
Maintenance cost for 10 Years & $75.000 \$$ & $16.800 \$$ & $16.000 \$$ \\
\hline Cost consists of maintenance and replacement cost of lamp and Ballast+labor+extra expenses.
\end{tabular}

Table 6. Analysis of ROI

\begin{tabular}{lllll}
\hline Factors & Conventional light (USD) & LED light (USD) & Saving (USD) & ROI (USD) \\
\hline 0 & 20,000 & 70,000 & ------ & $-50,000$ \\
$1^{\text {st }}$ year & 28,500 & 9,480 & 19,020 & $-30,980$ \\
$2^{\text {nd }}$ year & 33,500 & 9,480 & 24,020 & $-6,960$ \\
$3^{\text {rd }}$ year & 28,500 & 9,480 & 19,020 & 12,060 \\
$4^{\text {th }}$ year & 33,500 & 9,480 & 24,020 & 36,084 \\
$5^{\text {th }}$ year & 28,500 & 9,480 & 19,020 & 55,108 \\
$6^{\text {th }}$ year & 33,500 & 9,480 & 24,020 & 79,128 \\
$7^{\text {th }}$ year & 28,500 & 9,480 & 19,020 & 98,148 \\
$8^{\text {th }}$ year & 33,500 & 9,480 & 24,020 & 122,168 \\
$9^{\text {th }}$ year & 28,500 & 9,480 & 19,020 & 141,188 \\
$10^{\text {th }}$ year & 33,500 & 9,480 & 24,020 & 165,208 \\
\hline
\end{tabular}

Cost consists of the average cost of maintenance, replacing bulb, ballast, SMPS, and labor. Some of the advantages of LED for renewable energy are low energy utilization, long lifetime, high light output, better visibility, reduced light scattering, fast turn-on time, dimmable and controllable, as well as fewer optics aging. The results are applied by MATLAB version $17 \mathrm{~b}$ prototypical is built to evaluate the behavior of smart lighting street technology and renewable energy to reduce cost and energy consumption.

\section{CONCLUSION}

The benefits of LED street lights compared to HID are as follows: Improved safety and night time visibility by producing better color, eliminating dark areas between poles, and more uniform lighting distribution, Reduced upward light reflection which is the major causes of urban sky glow, Guarantees up to $40-80 \%$ energy efficiency conditional on the lighting source and the proposal standards, Saves up to 50-75\% cost of smart LED maintenance. On the other hand, there are two main drawbacks of LED, one is the cost of an LED street lamp a reasonable initial capital is needed as they are about 2-8 times costlier than the traditional HID. The quick progress of LED-based light and the related skills offered new perspectives for the strategy and regulator of street lighting systems. Being that each device is manufactured with different materials and technology, their operation hours differed considerably. This was demonstrated by natural light procedures using a digital illuminance meter in Iraq. 


\section{REFERENCES}

[1] Angelle, Amber, "Will LED Light Bulbs Best Your CFLs and Incandescent?," 2010. [Online]. Available: http://www.popularmechanics.com/science/environment/will-led-light-bulbs-best-cfls-and-incandescents.

[2] M. S. A. Mustafa, M. A. M. Arif, Sofia Najwa Ramli, "An extensive review of energy storage system for the residential renewable energy system," Indonesian Journal of Electrical Engineering and Computer Science (IJEECS), vol. 18, no. 1, pp. 242-250, 2020.

[3] Shahzad, G., Yang, H., Ahmad, A. W., Lee, C., "Energy-Efficient Intelligent Street Lighting System Using TrafficAdaptive Control," in IEEE Sensors Journal, vol. 16, no. 13, pp. 5397-5405, 2016.

[4] Soh, C. B., Tan, J. W. J., Tseng, K. J., lok Woo, W., Teo, J. W. R., "Intelligent Street Lighting for Smart Cities," 2018 IEEE Innovative Smart Grid Technologies-Asia (ISGT Asia), Singapore, pp. 1027-1031, 2018.

[5] Design Recycle Inc., "Comparison Chart: LED Lights vs. Incandescent Light Bulbs vs. CFLs," 2011. [Online]. Available: http://www.designrecycleinc.com/led\%20comp\%20chart.html;Fun-led-light.

[6] "Ministerio de Minas y Energía. Anexo General. Reglamento Técnico de Iluminación y Alumbrado Público; RETILAP: Colombia,” 2010. [Online]. Available: http://www.minminas.gov.co/minminas/ downloads/archivos Soporte Revistas/7853.pdf.

[7] "The Government of the Hong Kong Special Administrative Region. Public Lighting Design Manual," 2015. [Online]. Available online: http://www.oshc.org.hk/others/bookshelf/WB112003E.pdf.

[8] SewellDirect.com, "LED vs. CFL vs. Incandescent Light Bulbs," 2011. [Online]. Available: http://sewelldirect.com/articles/led-vs-incandescent-light-bulbs.aspx.

[9] Khatavkar, N., Naik, A. A., Kadam, B., "Energy efficient street light controller for smart cities," 2017 International conference on Microelectronic Devices, Circuits and Systems (ICMDCS), Vellore, pp. 1-6, 2017.

[10] Mahoor, M., Salamis, F. R., Najafabadi, T. A., "A Hierarchical Smart Street Lighting System with Brute-Force Energy Optimization,” in IEEE Sensors Journal, vol. 17, no. 9, pp. 2871-2879, 2017.

[11] "Echelon Corporation, Monitored Outdoor Lighting White Paper," 2020. [Online]. Available: http://www.echelon.com/solutions/streetlight/documents/Echelon_StreetlightWhitepaper_FINAL.

[12] Hegedus, S. and A. Luque, "Achievements and challenges of solar electricity from photovoltaics," Handbook of Photovoltaic Science and Engineering, Second Edition, pp. 1-38, 2010.

[13] Carli, R., Dotoli, M., Pellegrino, R., "ICT and optimization for the energy management of smart cities: The street lighting decision panel," 2015 IEEE 20th Conference on Emerging Technologies \& Factory Automation (ETFA), Luxembourg, pp. 1-6, 2015.

[14] A. A. Ashryatov, V. G. Kulikov, A. V. Panteleyev, "Energy saving control system development for external lighting," Indonesian Journal of Electrical Engineering and Computer Science (IJEECS), vol. 17, no. 3, pp. 1601-1606, 2020.

[15] "Power Integrations, Streetlight Design Reference document," [Online]. Available: http://www.powerint.com/sites/default/files/PDFFiles/der212.

[16] "OSRAM, Street Lighting with LED Sources Application Note," [Online]. Available: http://catalog.osramos.com/catalogue/catalogue.do?favOid=0000000300012fdd018a00b7\&act=showBookmark.

[17] Kaleem, Z., Ahmad, I., Lee, C., "Smart and Energy Efficient LED Street Light Control System Using ZigBee Network," 2014 12th International Conference on Frontiers of Information Technology, Islamabad, pp. 361-365, 2014.

[18] American Association of State Highway and Transportation Officials (AASHTO), "Designing for Environmental Stewardship,” 2010. [Online]. Available: https://www.transportation.org/.

[19] LEDTele.co.uk, "LED vs. LCD TV Comparison," 2011. [Online]. Available: http://www.ledtele.co.uk/ledvslcd.html.

[20] Adam Sẹdziwy, "A New Approach to Street Lighting Design," LEUKOS The Journal of the Illuminating Engineering Society of North America, vol. 12, no. 3, pp. 1-12, 2015.

[21] G. Muni Reddy, T. Gowri Manohar, "Fuzzy Logic Controller for grid connected Wind Energy Conversion System," Indonesian Journal of Electrical Engineering and Informatics (IJEEI), vol. 6, no. 1, pp. 37-44, 2018.

[22] Muhammad M. A. S. Mahmoud, "Typical economic model for calculating the saving norm of replacement HPS street lighting by LED fixtures in access road of gas production company at GCC," 2018 5th International Conference on Electrical and Electronic Engineering (ICEEE), Istanbul, pp. 189-192, 2018.

[23] Mud Dasani Satyanarayana, P. Satish Kumar, "Analysis and Design of Solar Photo voltaic Grid Connected Inverter," Indonesian Journal of Electrical Engineering and Informatics (IJEEI), vol. 3, no. 4, pp. 199-208, 2015.

[24] Mohamed Habibie, Rafhanah Rosli, Md Rafiqul Islam, "RSSI-based Human Presence Detection System for Energy Saving Automation," Indonesian Journal of Electrical Engineering and Informatics (IJEEI), vol. 5, no. 4, pp. 339-350, 2017.

[25] Krishan Kumar, M. A. Ansari, "Evaluation of Power Management Strategy for Renewable Microgrid System," Indonesian Journal of Electrical Engineering and Informatics (IJEEI), vol 6, no. 2, pp. 133-142, 2018. 